\title{
The potential of satellite radar altimetry in flood forecasting: concept and implementation for the Niger-Benue river basin
}

\author{
R. Pandey and G. Amarnath \\ International Water Management Institute (IWMI), Colombo, Sri Lanka \\ Correspondence to: R. Pandey (r.pandey@cgiar.org); G. Amarnath (a.giriraj@cgiar.org) \\ Received: 11 March 2015 - Accepted: 11 March 2015 - Published: 11 June 2015
}

\begin{abstract}
Flood forecasting in the downstream part of any hydrological basin is extremely difficult due to the lack of basin-wide hydrological information in near real-time and the absence of a data-sharing treaty among the transboundary nations. The accuracy of forecasts emerging from a hydrological model could be compromised without prior knowledge of the day-to-day flow regulation at different locations upstream of the Niger and Benue rivers. Only satellite altimeter monitoring allows us to identify the actual river levels upstream that reflect the human intervention at that location. This is critical for making accurate downstream forecasts. This present study aims to demonstrate the capability of altimeter-based flood forecasting along the Niger-Benue River in Nigeria. The study includes the comparison of decadal (at every 10 days from Jason-2) or monthly (at every 35 days from Envisat/AltiKa) observations from 2002 to 2014, with historical in situ measurements from 1990 to 2012. The water level obtained from these sources shows a good correlation (0.7-0.9). After validation of hydrological parameters obtained from two sources, a quantitative relation (rating curve) of upstream water level and downstream discharge is derived. This relation is then adopted for calculation of discharge at observation points, which is used to propagate the flow downstream at a desired location using a hydraulic river model. Results from this study from Jason-2 shows a promising correlation $\left(R^{2} \geq 90 \%\right.$ with a Nash-Sutcliffe coefficient of more than 0.70 ) with 5 days ahead of downstream flow prediction over the Benue stream.
\end{abstract}

\section{Introduction}

River flow measurements are critical for hydrological data assimilation and model calibration in flood forecasting, and for other water resources management issues. In many parts of the world, however, in situ river discharge measurements are either completely unavailable or are difficult to access for timely use in operational flood forecasting and disaster mitigation (Biancamaria et al., 2011). Radar altimetry measures the distance between the satellite and instantaneous water surface. The differences between the satellite altitude, relative to a reference ellipsoid determined through precise orbit computation, and the distance from the satellite to the water surface provides a measurement of the water level above the datum. In order to obtain the height of the water surface, various corrections have to be added, such as the time delay related to the propagation of the pulse through the atmo- sphere (dry and wet tropospheric correction) and the ionosphere (Ionospheric correction), and the correction for solid tidal effects on the Earth (Fu and Cazenave, 2001).

Several water elevation and discharge estimation attempts have been made based on satellite altimetry for the Amazon, Ganges and Brahmaputra rivers. Siddique-E-Akbor et al. (2011) compared the water elevation derived from Envisat satellite altimetry with simulated water levels from the HECRAS model for three rivers in Bangladesh, in which they reported the average (over 2 years) root mean square difference of $2.0 \mathrm{~m}$ between the simulated and the satellite-based water level estimates. In another study, Papa et al. (2010) produced estimates of monthly discharges for the Ganges and Brahmaputra rivers using TOPEX-Poseidon (T-P), ERS2 and ENVISAT satellite altimetry information. Biancamaria et al. (2011) also used T-P satellite altimetry measurements of the water level at upstream locations in India to forecast 


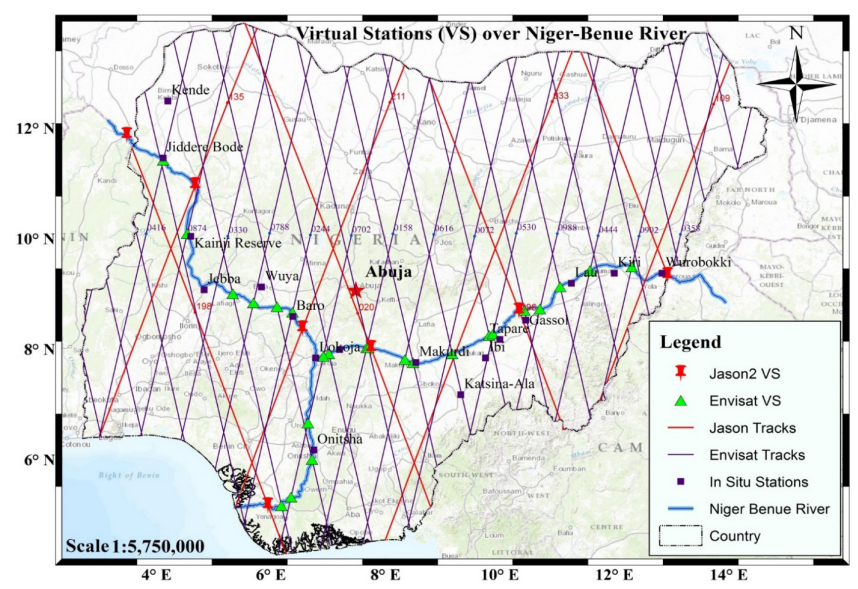

Figure 1. Location map of the Niger-Benue River (blue line) with altimetry tracks (Jason-2 in red and Envisat/Altika in purple).

water levels for the Ganges and Brahmaputra rivers after they cross the India-Bangladesh border.

Based on the above insights, this study proposes a simple methodology to estimate the discharge along rivers using "rating curves" principles, even those poorly gauged, taking advantage of water level measurements derived from satellite altimetry. We also evaluate the relationship between upstream and downstream linkages to develop forecast rating curves to primarily provide flood early warning in the downstream region to minimize the impact of disasters.

\section{Materials and methods}

This present study is carried out along the Niger-Benue River in Nigeria. A schematic diagram of a cross-section of satellite altimeter ground track with the river, known as Virtual Station, is shown in Fig. 1. Straight lines are altimetry tracks (red lines represent Jason-2 and purple lines represent Envisat/AltiKa tracks) over Nigeria. The different virtual stations over the rivers are marked with a green triangle and red pin for Envisat/AltiKa and Jason-2 missions, respectively.

The various altimetry observations used in this study are obtained from CTOH (Envisat data, http://ctoh.legos. obs-mip.fr/) and AVISO (AltiKa and Jason-2; ftp://avisoftp. cnes.fr) for the period from 2002 to 2014. The altimeter data range, a distance between the satellite and water bodies, along with various correction parameters ( $\mathrm{Fu}$ and Cazenave, 2001), are used in Virtual Altimetry Station (VALS) software (Santos da Silva et al., 2010) for generating water level $(h)$ at defined virtual stations using Eq. (1).

$h=A-R+C_{\text {iono }}+C_{\text {dry }}+C_{\text {wet }}+C_{\text {st }}+C_{\mathrm{pt}}$,

where $C$ denotes the corrections applied due to a delay in pulse propagation through the ionosphere (subscript "iono'), and humid ("wet") and dry atmospheres ("dry"). $C_{\mathrm{pt}}$ and $C_{\mathrm{st}}$ eliminate the effect of the polar tide and solid earth tide, respectively, on estimated height. $A$ and $R$ refer to satellite altitude and the one-way distance travelled by radar pulse, respectively.

Long-term historical datasets of water level and discharge were obtained from Nigeria Hydrological Services Agency (NIHSA). These in situ measurements are employed for training and validation of the model in this study. Comparison of estimated water level with in situ measurement is carried out by considering statistical adjustment of the reference level of two water level sources (Siddique-E-Akbor et al., 2011). The difference in the mean of two water levels is added to the in situ measurement to bring both time series to same water level.

An empirical relationship, referred to as "Forecast Rating Curve (FRC)", is developed for forecasting the X days of lead travel time at upstream water level with downstream (in situ) discharge for a particular period of time. The relationship derived is then used to estimate discharge at a downstream location against the water level at an upstream virtual station, and further propagated downstream using the hydrodynamic model established from HEC-RAS. We have used the HEC-RAS model from Hydrologic Engineering Center (HEC), US Army Corps of Engineers, to produce a surface water profile. In the process of establishing FRCs, the water level derived from the altimeter is compared with the daily water level measurement obtained from NIHSA to determine the lead period (up to 20 days) of forecasting (Biancamaria et al., 2011). Altimeter-derived water level, its comparison with in situ observations and establishment of prediction lead period are discussed in Sect. 3 followed by the conclusion.

\section{Results and discussion}

\subsection{Comparison between ENVISAT, Jason-2 data with in situ water level data}

At more than 35 locations across the Benue-Niger River (Fig. 1), the water level is derived from Envisat, Jason2 and AltiKa missions. The water level derived shows a very good seasonal peak to variation. A water level time series analysis from 2002 to 2014 is shown in Fig. 2a. In most of the cases, the historical flood events are captured in the water level estimation from altimeter measurements (Nigeria, 2012), e.g., high water level along the Benue River during the 2012 flood event after the release of water from Cameroon is well recorded (Figs. 2 and 3). The time series in Fig. 2a at upstream Makurdi (Fig. 1) along the Benue stream presents a variation in water elevation estimated from Envisat (Envisat_773, orange color, lat $=8.694^{\circ}$, long $=10.4266^{\circ}$ ) and Jason-2 (Jason2_96, black color, lat $=8.6797^{\circ}$, long $=10.3429^{\circ}$ ). The time series (Fig. 2a) contain the water level estimates from Envisat (2002 to 2011) and Jason-2 (since mid-2008) observations. 

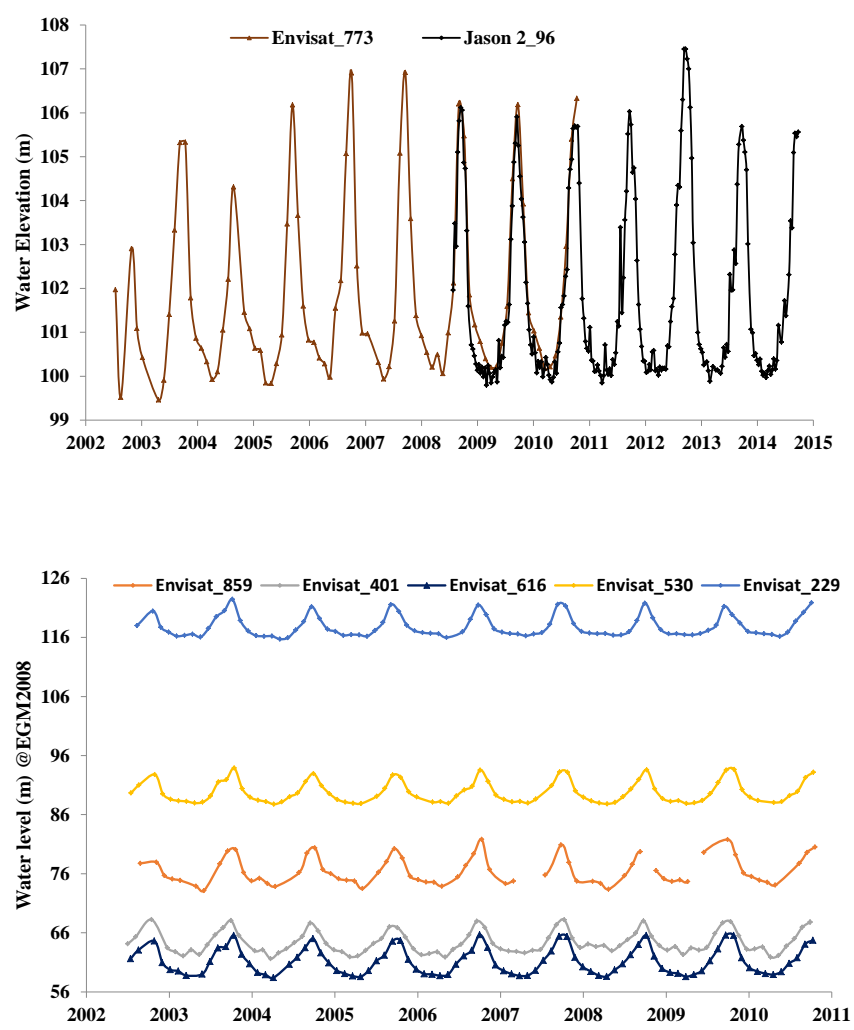

Figure 2. (a) A water level time series derived from radar altimetry observed at Makurdi gauging station. (b) Water level derived from several virtual stations from Envisat track along the Benue River.

Although the variation in water level from both missions, Envisat and Jason-2, are calculated in relation to a same reference level (Earth Gravitational Model EGM2008), a biasing of $0.95 \mathrm{~m}$ is found among them and adjusted in deriving historical to current water level variations. It can be noted that the water level for the overlapping period from 2008 to 2010 from the two missions shows a good agreement. Figure $2 b$ presents water elevation at different locations along the upper stream of the Benue River. Water elevation profiles, in Fig. 2b, shows a good peak to peak correlation and seasonal variability in water level. The water level variation from upstream to downstream at different virtual stations, across the Benue River, is in the order of 8 to $6 \mathrm{~m}$.

Similar to any modelled or space-derived products, the estimated water level from altimeter also requires validation with ground truthing. Validation of the water level derived from altimeter observations are carried out with in situ daily water level measurements accessed from NIHSA, Nigeria. A comparison of water levels derived from Jason-2 with in situ measurements is shown in Fig. 3. A high correlation $\left(R^{2}=0.95\right)$ in the magnitude of the water level derived and in situ measurements is observed. Similar kinds of results are obtained at other locations along the river system in thand $95 \%$ e study area, where correlation coefficient varies between 70 at different locations and time periods of a year

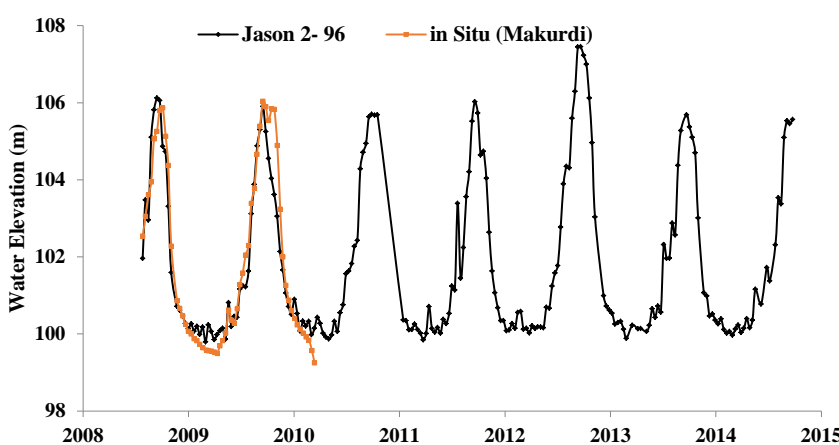

Figure 3. Comparison of in situ (orange) at Makurdi stations with Jason-2 derived water elevation (black) along the Benue River.

given the different hydrogeological setup. A double peak is observed in in situ water level, which is absent in the altimeter-derived water level shown in Fig. 3. This can be explained by considering the fact that two measurements are not at the same location, but are within a few kilometers apart (Papa et al., 2010), and between these distances there can be additional inflow from tributaries and runoff from nearby catchments.

\subsection{Operational forecasts for real-time decision making}

After estimation of the water level from altimeter and its validation, the water level derived is used to establish an empirical relation referred to as "FRC" (Hossain et al., 2014). FRC is a relationship between the upstream water level and downstream discharge, and is deployed for estimation of discharge in advance using the rating curve technique at the point of altimetric observation and, subsequently, its propagation downstream to obtain the surface water profile. During this process, we first compared the upstream water level, obtained from the altimeter, with downstream in situ discharge with a different lead time of up to 20 days. The correlation is better for a lower lead period compared to a longer lead period, as expected. A relationship between altimeter-derived water level (at virtual station for Jason-2 track number 96) and in situ water level with a lead period of 5 days is presented in Fig. 4.

The empirical relationship shows a correlation of about $97 \%$ for the period of data from mid-2008 to mid-2009 with a Nash-Sutcliffe efficiency coefficient of more than 0.7. From the scatterplot in Fig. 4, it can be noted that the correlation for a high water level is comparatively low. Using the derived rating curve equation, estimated discharge is shown in Fig. 5. A comparison of the discharge derived (blue dotted line) with in situ measurement (orange dotted line) shows an underestimated discharge from altimetry. The underestimated value ranges between 5 and $22 \%$, but shows good qualitative correlation which is well within the range of globally accepted error in estimation (Papa et al., 2010). The underestimated value may increase because of the inflow from tributaries and 


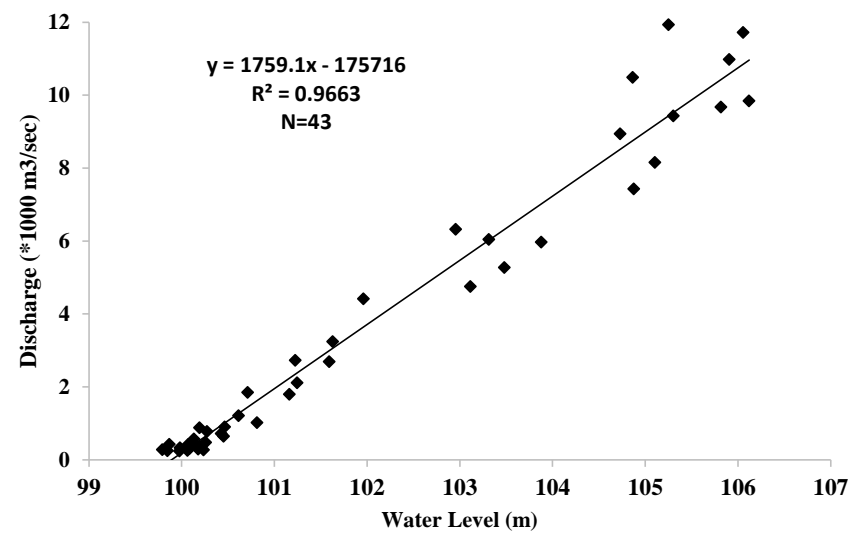

Figure 4. Rating curve with a lead time of 5 days for Jason-2 at ground track (virtual stations) number 96 (Benue River - Fig. 1) for Makurdi stations for the period July 2008 to August 2009.

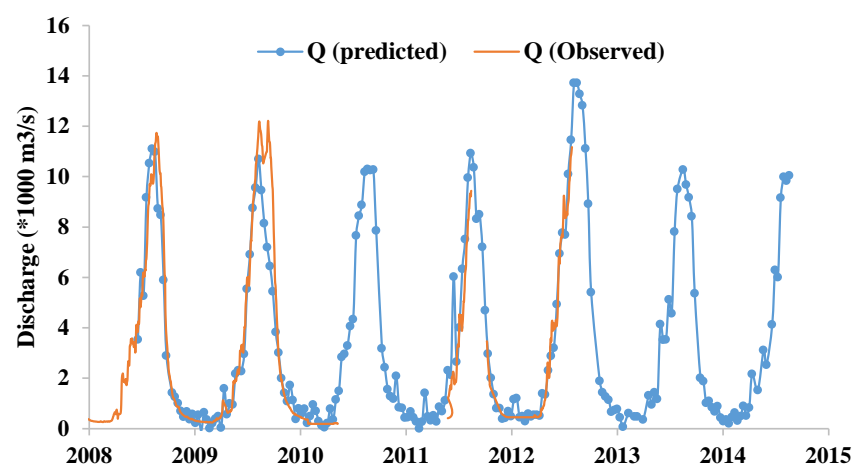

Figure 5. Discharge derived with a lead time of 5 days for estimated and observed values between satellite altimetry at virtual stations and Makurdi in-situ observations.

local catchments. The same argument can be extended for the absence of double peaks of discharge in 2009 (Fig. 5).

A correlation of more than $90 \%$ is found among comparative studies between discharge estimated from observed Rating Curve (RC) (in situ water level versus in situ discharge) with derived RC (altimeter-derived water level versus in situ discharge). Although the derived RC is carrying the error from water level estimation in the order of a few decimeters (Birkett et al., 2002; Crétaux et al., 2005; Frappart et al., 2006; Santos da Silva et al., 2010), the derived discharge shows a good correlation in magnitude.

\section{Conclusions}

Improvements in spaceborne measurements provide a good alternative for the study of various hydrological problems. The current work demonstrates one such issue of estimating water level over a fairly wide reach of the river in Nigeria from altimeter measurements. Further, we have, in our study, tried to answer the question of flood prediction using the derived water level from altimeter in Nigeria, by calculat- ing the discharge and propagating it using the hydrodynamic modelling to derive the surface water elevation of river water downstream. The study includes validation of space-derived products with in situ measurements, followed by deriving a quantitative stage discharge relation. At more than 30 virtual stations, the water level from different missions is estimated starting from 2002 to the present depending on mission data. A long-term time series was obtained for four virtual stations, where the distance between the virtual stations for different missions is less than $20 \mathrm{~km}$ (e.g., a combined time series for Envisat-773 and Jason 2-96, Fig. 2). The results obtained from the altimetry at different virtual stations show a good inter-annual trend along the river stream in Nigeria. The comparison of estimated water elevation with in situ observations also shows a promising result, which can be used for hydrological studies in the absence of conventional data.

It has been found that altimeter-derived discharge, estimated from stage-discharge relation, at the point of crosssection of ground tracks of satellite pass with the river stream shows a very good correlation with in situ measures. Estimated discharge from the rating curve (FRC, in the case of forecasting) at individual locations exhibits strong seasonality and is well within the globally accepted error range in magnitude of discharge. It is equally important to highlight the limitations of altimetric use for riverine-related studies. The (river) width is one critical parameter for estimation of water height. From available missions and re-tracking algorithms, so far the water level estimation is carried out for a width of over $100 \mathrm{~m}$, which will be improved by twofold with the proposed Surface Water and Ocean Topography (SWOT) mission. Other limitations are the selection of a re-tracing algorithm, temporal resolution and contamination of signal in the case of a braided channel.

Acknowledgements. This research was funded by the Federal Ministry of Agriculture and Rural Development (FMARD), Nigeria, the CGIAR Research Program on Water, Land and Ecosystems (WLE) and the International Water Management Institute (IWMI). We would like to thank Vladimir Smakhtin (Theme Leader - Water Availability, Risk and Resilience, IWMI) and Timothy Williams (Director, Africa, IWMI) for their inspiring guidance and encouragement, and also thank Nigeria Hydrological Services Agency (NIHSA) for sharing in situ observations.

\section{References}

Biancamaria, S., Hossain, F., and Lettenmaier, D. P.: Forecasting transboundary river water elevations from space, Geophys. Res. Lett. 38, L11401, doi:10.1029/2011GL047290, 2011.

Birkett, C. M., Mertes, L. A. K., Dunne, T., Costa, M. H., and Jasinski, M. J.: Water Dynamics in the Amazon Basin: Application of Satellite Radar Altimetry. Journal of Geophysical Research, 107, 8059, doi:10.1029/2001JD000609, 2002.

Crétaux, J. F., Kouraev, A. V., Papa, F., Bergé-Nguyen, M., Cazenave, A., Aladin, N., and Plotnikov, I. S.: Evolution of sea 
level of the big Aral Sea from satellite altimetry and its implications for water balance, J. Great Lakes Res., 31, 520-534, 2005.

Frappart, F., Dominh, K., Lhermitte, J., Ramilllien, G., Cazenave, A., and LeToan, T.: Water volume change in the lower Mekong Basin from satellite altimetry and imagery data, Geophys. J. Int., 167, 570-584, 2006.

Fu, L. L. and Cazenave, A. (Eds.): Satellite Altimetry and Earth Sciences: A Handbook of Techniques and Application, Int. Geophys. Ser., vol. 69, San Diego, CA, Academic Press, 37-57, 2001.

Hossain, F., Siddique-E-Akbor, A. H. M., Mazumder, L. C., ShahNewaz, S. M., Biancamaria, S., Lee, H., and Shum, C. K.: Proof of Concept of an Operational Altimeter-based Forecasting System for Transboundary Flow. IEEE J. Select. Top. Appl. Remote Sens., 7, 587-601, doi:10.1109/JSTARS.2013.2283402, 2014. \%bibitem1 Nigeria: Floods - Jul 2012, http://reliefweb.int/ disaster/fl-2012-000138-nga (last access: August 2014), 2012.
Papa, F., Durand, F., Rossow, W. B., Rahman, A., and Bala, S. K.: Satellite Altimeter Derived Monthly Discharge of the Ganga Brahmaputra River and its Seasonal to Interannual Variations from 1993 to 2008, J. Geophys. Res., 115, C12013, doi:10.1029/2009JC006075, 2010.

Santos da Silva, J., Calmant, S., Seyler F., Filho, O. C. R., Cochonneau, G., and Mansur, W. J.: Water levels in the Amazon basin derived from the ERS 2 and ENVISAT radar altimetry missions, Remote Sens. Environ, 114, 2160-2181, doi:10.1016/j.rse.2010.04.020, 2010.

Siddique-E-Akbor, A. H., Hossain, F., Lee, H., and Shum, C. K.: Inter-comparison study of water level estimates derived from hydrodynamic-hydrologic model and satellite altimetry for a complex deltaic environment. Remote Sens. Environ. 115, 15221531, doi:10.1016/j.rse.2011.02.011, 2011. 